\title{
Causal and Putative Pathogenic Mutations Identified in $38.6 \%$ of Children with Primary SRNS in South Africa
}

\author{
Louansha Nandlal ( $\square$ loun0406@gmail.com) \\ University of KwaZulu-Natal Nelson R Mandela School of Medicine: University of KwaZulu-Natal College of Health Sciences \\ Cheryl A. Winkler \\ Frederick National Laboratory for Cancer Research \\ Rajendra Bhimma \\ University of KwaZulu-Natal Nelson R Mandela School of Medicine: University of KwaZulu-Natal College of Health Sciences \\ Sungkweon Cho \\ Frederick National Laboratory for Cancer Research \\ George W. Nelson \\ Frederick National Laboratory for Cancer Research \\ Sudesh Haripershad \\ University of KwaZulu-Natal Nelson R Mandela School of Medicine: University of KwaZulu-Natal College of Health Sciences \\ Thajasvarie Naicker \\ University of KwaZulu-Natal Nelson R Mandela School of Medicine: University of KwaZulu-Natal College of Health Sciences
}

\section{Research Article}

Keywords: paediatrics, SRNS, genetics, primary NS, South Africa

Posted Date: January 11th, 2022

DOI: https://doi.org/10.21203/rs.3.rs-1195453/v1

License: (c) (i) This work is licensed under a Creative Commons Attribution 4.0 International License. Read Full License 


\section{Abstract}

The aim was to identify causal mutations in genes implicated in steroid resistant nephrotic syndrome (SRNS) within a South African population. We enrolled 119 children with primary NS; 71 SRNS and 48 steroid-sensitive NS. All children with SRNS underwent kidney biopsy. We first genotyped the NPHS2 gene for the p.V260E variant in all NS cases $(n=119)$ and controls $(n=219)$. To further identify additional variants, we performed whole-exome sequencing and interrogated ten genes (NPHS1, NPHS2, WT1, LAMB2, ACTN4, TRPC6, INF2, CD2AP, PLCE1, MYO1E) implicated in SRNS/FSGS in 56 SRNS cases and 29 controls; we also performed exome sequencing on two patients carrying the NPHS2 p.V260E mutation as positive controls. The overall detection rate of pathogenic mutations in children with SRNS was 27/70(38.57\%): 15(21.43\%) carried the NPHS2 p.V260E mutation and 12(17.14\%) carried a pathogenic mutation in the heterozygous state in INF2 $(\mathrm{n}=8), \operatorname{CD} 2 A P(\mathrm{n}=3)$ or TRPC6 $(\mathrm{n}=1)$ genes. NPHS2 p.V260E homozygosity was specifically associated with biopsyproven FSGS, accounting for $23.81 \%$ of Black children (15 of 63) with SR-FSGS. No causal mutations were identified in NPHS1, WT1, LAMB2, PLCE1, MYO1E and ACTN4. We report four novel variants in INF2, PLCE1, ACTN4 and TRPC6.

Conclusion. The NPHS2 p.V260E mutation is a prevalent cause of SR-FSGS among Black South African children occurring in $23.81 \%$ of children with SRNS. Screening all Black African children presenting with NS for NPHS2 p.V260E will provide a precision diagnosis of SR-FSGS and inform clinical management.

\section{What Is Known}

- The high rate of steroid resistance in Black South African children with focal segmental glomerulosclerosis (FSGS) compared to other racial groups is partially explained by the founder variant NPHS2 p.V260E.

\section{What Is New}

- We report putative causal missense variants predicted to be pathogenic in INF2, CD2AP and TRPC6 among SR-FSGS children, demonstrating the utility of genetic testing for precision diagnosis of SR-FSGS to inform family planning and clinical management.

\section{Introduction}

Primary nephrotic syndrome (NS) is one of the most frequent glomerular diseases in childhood characterised by massive proteinuria, hypoalbuminemia, hyperlipidaemia and oedema ${ }^{[1,2]}$. Most children with primary NS have a gratifying response to conventional corticosteroid therapy with a good prognosis longterm. However, $10-20 \%$ of children show partial, late or complete resistance to corticosteroid therapy and are labelled as steroid-resistant NS (SRNS) ${ }^{[3,4]}$. SRNS continues to be one of the most common intractable causes of chronic kidney disease (CKD) in children with 50-70\% of these children developing progressive loss of kidney function leading to end-stage kidney disease (ESKD) within 5-10 years of diagnosis ${ }^{[5]}$. The therapeutic options in SRNS are often ineffective in inducing complete remission and complicated by significant toxicity adding to the morbidities, high cost, and sometimes even mortality associated with these therapies $^{[6]}$.

Previous studies emphasize the considerable influence of racial and geographical factors on steroid response, histopathological pattern and outcome of primary NS ${ }^{[7-9]}$. The two most common histopathological features noted in childhood NS are focal segmental glomerulosclerosis (FSGS) and minimal change disease (MCD $)^{[10]}$. The incidence of FSGS is higher in children of African ancestry compared to those of European ancestry ${ }^{[11-13]}$. In South Africa, the most common histological diagnosis in Black children is FSGS, whereas MCD is more frequently diagnosed in White and Indian children ${ }^{[14-16]}$. In a recent review of primary NS in the New Millennium at a tertiary/quaternary referral centre in Durban, KwaZulu-Natal, South Africa, the prevalence of FSGS in children was reported to be $70.1 \%$ of 209 children undergoing kidney biopsy; the prevalence in Black African children being as high as $73.5 \%{ }^{[17]}$. The higher prevalence rate of biopsy-proven SR-FSGS in children and adults, among certain ethnic groups, suggests the role of genetic susceptibility to disease ${ }^{[18]}$.

Mutations in several genes that are highly expressed in the glomerular filtration barrier and podocytes have been reported as causative agents in paediatric $\mathrm{NS}^{[19]}$. To date, more than 50 monogenic causes of SRNS (predominantly FSGS) have been identified displaying autosomal recessive (AR) or autosomal dominant $(A D)$ modes of inheritance ${ }^{[19]}$. Mutations in AR genes tend to present early in childhood whereas AD genes present later in childhood or adulthood and tend to be less penetrant ${ }^{[20,21]}$. Numerous genes encoding slit diaphragm proteins expressed by podocytes have recently been discovered and have been shown to be associated with primary SRNS ${ }^{[22]}$; including mutations in NPHS1, NPHS2, PLCEI, and MYO1E, showing AR inheritance and in ACTN4, TRPC6, IFN2 and $C D 2 A P$ showing $A D$ inheritance ${ }^{[23-27]}$. Genes encoding proteins related to transcriptional activity in podocytes, such as WT1 (AD inheritance) are also critical for podocyte integrity and function ${ }^{[28,29]}$. Additionally, AR mutations in $L A M B 2$ (AR) encoding laminin beta 2 are a cause of SRNS; $L A M B 2$ is secreted by podocytes and contributes to the configuration and spatial architecture of the glomerular basement membrane $\mathrm{e}^{[22,30]}$.

A precise genetic diagnosis in patients with SRNS is more conclusive than a histopathologic classification enabling a better prediction of prognosis to mediate clinical management of the child ${ }^{[31]}$. Like many genetic disorders, SRNS shows ethnic and geographic differences that may arise from founder or populationspecific mutations. In South Africa, there are limited genetic studies on childhood-onset NS. Asharam et al. identified a common founder mutation NPHS2 p.V260E variant accounting for a third or more of SR-FSGS in Black South African children living in the KwaZulu-Natal province ${ }^{[18]}$; this association was extended to other black ethnic groups ${ }^{[32]}$. However, further research is required to identify additional mutations that account for the high rate of SRNS in South African Black children. This study aimed to screen for causal mutations in ten genes (NPHS1, NPHS2, WT1, LAMB2, ACTN4, TRPC6, INF2, CD2AP, PLCE1, MYO1E) previously associated with SRNS, in a South African population with primary SRNS seen at a tertiary hospital in KwaZulu-Natal, South Africa.

\section{Material And Methods}




\section{Study participants}

This study protocol was reviewed and approved by Biomedical Research Ethics Committee of the University of KwaZulu-Natal and Department of Health, KwaZulu-Natal, South Africa, approval number BE374/17. Children 1-18 years old with primary NS ( $\mathrm{n}=118$ ) and biopsy-proven FSGS treated between January 2000 to February 2019 at Inkosi Albert Luthuli Central and King Edward VIII Hospital in Durban, KwaZulu-Natal, South Africa, were enrolled in the study. Children that were HIV negative, with no kidney disease and similar geographic and ethnic backgrounds, were enrolled as the control group ( $\mathrm{n}=219$ ). Patients with incomplete data, indeterminate histopathology, congenital NS, secondary forms of NS, and those lost to follow-up (defined as a patient not having contact with the hospital/clinic for 180 days or more since their last recorded expected date) or who refused to participate in the study, were excluded.

\section{Data capture}

All patient data was extracted from the hospitals electronic records using MEDITECH ${ }^{\circledR}$. Hypertension was defined by the Fourth Report on the Diagnosis, Evaluation, and Treatment of High Blood Pressure in Children and Adolescents as follows: normal if <90th percentile; prehypertension if $\geq 90$ th to <95th percentile or $>120 / 80 \mathrm{mmHg}$ in adolescents; Stage $1 \mathrm{HPT}$ if between $\geq 95$ th to 99 th percentile plus $5 \mathrm{mmHg}$; Stage 2 HPT if $>99$ th percentile plus 5 $\mathrm{mmHg}^{[33]}$. Patients estimated glomerular filtration rate (eGFR) was calculated using the modified Schwartz formula ${ }^{[34,35]}$ and children were classified according to Kidney Disease Outcomes Quality Initiative (KDIGO) guidelines for CKD ${ }^{[36]}$.

\section{Treatment}

All children with primary NS were given oral prednisone at a dose of $2 \mathrm{mg} / \mathrm{kg}$ (maximum $60 \mathrm{mg}$ ) for six weeks, followed by the same dose on alternative days for another six weeks, and reduced to none over a two and a half-month period. Failure to respond to oral steroids after six weeks was taken as steroid resistance in accordance with standard criteria ${ }^{[4]}$. Following a kidney biopsy, treatment for children with SRNS included inter alia intravenous pulse methylprednisolone and cyclophosphamide, calcineurin inhibitors (cyclosporin A, or tacrolimus) and mycophenolate mofetil in combination with low dose oral steroid and angiotensin-converting enzyme antagonists. All patients also received multivitamins and folic acid supplements.

\section{Kidney biopsy}

Examination of kidney biopsies was performed by light, fluorescent and electron microscopy. Histologic criteria for MCD were normal glomeruli by light microscopy, including the absence of segmental sclerosis and thickening of the glomerular basement membrane, and absence of significant deposits by immunofluorescence study. FSGS was defined as a histopathological lesion characterized by the presence of sclerosis in parts (segmental) of some (focal) glomeruli. FSGS was classified histopathologically according to the Columbia classification into the following categories: (i) classical FSGS or FSGS not otherwise specified, (ii) collapsing variant, (iii) tip variant, (iv) perihilar variant and (v) cellular variant.

\section{DNA Extraction and Sequencing}

Genomic DNA was extracted from whole blood using the ThermoFisher Scientific GeneJet DNA Purification Mini Kit as per manufacturers guidelines (Waltham, MA). We first genotyped the NPHS2 gene for the p.V260E variant in SSNS ( $n=48)$, SRNS ( $n=70)$ cases and controls ( $n=219)$ (Figure 1$)$ using TaqMan assay (ThermoFisher Applied Biosystems, Waltham, MA), since previous studies identified this mutation as the most frequent Mendelian cause of SRNS in Black South African children with both familial and sporadic disease ${ }^{[18,32]}$. To identify additional variants, we performed whole-exome sequencing (WES) in 56 SRNS cases and 29 controls; we also performed exome sequencing on two patients carrying the NPHS2 p.V260E mutation as positive controls. WES was performed by LC Sciences (Huston, TX). Extracted DNA underwent library prep according to the Agilent SureSelect XT (All Exon V5 +UTR) protocol and sequenced on Illumina HiSeq4000 device using paired-end sequencing to an average sequencing depth of $>80 x$. Image analysis and base calling were performed with the pipeline software using default parameters. Mapping was done using the human reference genome assembly (GRCh37/hg19).

\section{WES variant filtering analysis}

We limited our analysis of the WES sequencing results to variants in ten genes (NPHS1, NPHS2, WT1, LAMB2, ACTN4, TRPC6, INF2, CD2AP, PLCE1, MYO1E) implicated in SRNS/FSGS. We followed standard guidelines of investigating variants for Mendelian disorders from WES data ${ }^{[37,38]}$. Alignment and variant calling was performed with the Centre for Cancer Research Collaborative Bioinformatics Resource (CCBR) pipeline (https://github.com/CCBR/Pipeliner). Due to our small sample size, we interrogated the top ten genes associated with childhood SRNS using analytical methodologies from Gee et a[39] and Sperling et al. ${ }^{[40]}$. Variants present in the homozygous or heterozygous state in control samples were excluded. Only protein-altering (missense) variants, insertion/deletion (indel), or splice-site variants were selected. In further filtering, we included single heterozygous variants that were not present in controls. The relatedness of samples was calculated using the kinship coefficient.

\section{Statistical analysis}

Data analysis was performed using Graph pad prism 5 software (Graph Pad Software, San Diego, CA, USA). The descriptive analysis was performed by calculating the means and standard deviations for continuous variables or numbers and percentages for categorical variables. All the data were normally distributed and tested using the Kolmogorov Smirnov test. A comparative analysis between two groups was calculated using a two-sample t-test for comparing the means and a Chi-square test for comparing categorical variables. Comparison of the distribution of age of onset in children carrying the mutation was calculated using one-way analysis of variance. A p-value $<0.05$ was considered statistically significant, except in the case of multiple comparisons where we corrected for gene number.

\section{Results}




\section{Clinical characteristics}

One hundred and eighteen children with primary NS were enrolled in this study; 70 children had SRNS and 48 children had steroid-sensitive (SSNS) (Figure 1). Pairwise inbreeding coefficient tests in PLINK showed no evidence of consanguinity among the 70 children and no evidence of relatedness among cases carrying causal or putative mutations. Sixty-three (90.00\%) children with SRNS were Black African and seven (10.00\%) were Indian. Nine (18.75\%) children with SSNS were Black African and 39 (81.25\%) were Indian. SRNS was much more frequent among Black children with NS; $87.50 \%$ Blacks vs. $15.22 \%$ Indians (95\% Cl: $0.52-0.91 ; p<0.0001)$. FSGS was the most common histopathological finding present in 67 (95.71\%) children. MCD was present in three (4.29\%) children. According to the Columbian classification of the 67 FSGS cases, 40 (59.70\%) children had a histopathological finding characterised as not otherwise specified, 20 (29.85\%) had cellular variant, two (2.99\%) collapsing variant, one (1.49\%) had a tip variant and four (5.97\%) were not categorizable as there was a mixed histology.

Clinical and laboratory data of children presenting with SRNS and SSNS are presented in Table 1. Children with SRNS (mean 99.79; $95 \%$ Cl: 88.48-111.10 months) presented at a much older age than children with SSNS (mean 63.71; 95\% Cl: 49.66-77.75 months; $p=0.001$ ). At disease presentation, mean urinary protein creatinine ratio was significantly increased in children with SRNS (mean 2.35; 95\% Cl: 2.19-4.01 g/mmol) compared to SSNS (mean 0.88; $95 \%$ Cl: 0.64$1.13 \mathrm{~g} / \mathrm{mmol} ; p=0.017$ ). A significantly higher mean serum cholesterol levels were also noted in children with SRNS (mean 7.57; $95 \% \mathrm{Cl}: 6.66-8.48 \mathrm{mmol} / \mathrm{l})$ vs. SSNS (mean 6.04; 95\% Cl: 5.51-7.23 mmol/l; $p=0.013$ ). Serum albumin levels were increased in children with SRNS (mean $29.58 ; 95 \% \mathrm{Cl}$ : $21.97-28.33 \mathrm{~g} / \mathrm{l}$ ) when compared to SSNS (mean 28.53; $95 \% \mathrm{Cl}$ : $25.70-31.36 \mathrm{~g} / \mathrm{l}$ ), albeit non-significant ( $p=0.22$ ). Among children with SRNS, the mean period of follow-up was 25.11 months (95\% Cl: 19.12-31.10 months). At last hospital visit, 41(57.74\%) patients had a normal eGFR, 22(30.99\%) patients progressed to CKD stages IIIV, and $8(11.27 \%)$ progressed to ESKD. Three children received a kidney transplant from a related living donor and five were on maintenance dialysis. None of the children who were transplanted had a recurrence of the disease in the transplanted kidney.

Table 1

Clinical and demographic characteristics of primary steroid resistant nephrotic syndrome and steroid sensitive nephrotic syndrome cases

\begin{tabular}{|c|c|c|c|}
\hline Clinical and biological data & SSNS (mean $\pm S D)$ & SRNS (mean $\pm S D)$ & $p$ value \\
\hline $\mathbf{N}$ & 48 & 70 & \\
\hline Female & 16 & 36 & \\
\hline Male & 34 & 34 & \\
\hline Ethnicity & & & $<0.0001$ \\
\hline Black & $9(18.75 \%)$ & $63(90.00 \%)$ & \\
\hline Indian & $39(81.25 \%)$ & $7(10.00 \%)$ & \\
\hline Age at onset (months) & $63.71 \pm 48.37$ & $99.79 \pm 46.75$ & 0.001 \\
\hline BMI (kg.m²) & $15.68 \pm 7.84$ & $20.35 \pm 4.82$ & 0.013 \\
\hline \multicolumn{4}{|l|}{ Blood pressure (mmHg) } \\
\hline Normotensive & $24(48 \%)$ & $34(48.57 \%)$ & \\
\hline Stage 1 & $14(28 \%)$ & $21(30 \%)$ & \\
\hline Stage 2 & $8(16 \%)$ & $15(21.43 \%)$ & \\
\hline Presence of oedema & $19(38 \%)$ & 31 (44.29\%) & \\
\hline \multicolumn{4}{|l|}{ Histology } \\
\hline FSGS & & $67(95.71 \%)$ & \\
\hline MCD & & $3(4.29 \%)$ & \\
\hline Other histology & & 0 & \\
\hline uPCR (g/mmol) & $0.88 \pm 1.01$ & $2.35 \pm 4.97$ & 0.017 \\
\hline Serum albumin $(g / L)$ & $28.53 \pm 11.33$ & $29.58 \pm 10.78$ & 0.22 \\
\hline Serum cholesterol (mmol/L) & $6.04 \pm 2.76$ & $7.57 \pm 3.31$ & 0.013 \\
\hline Duration of follow up (months) & $45.36 \pm 37.20$ & $25.11 \pm 25.68$ & 0.0078 \\
\hline ESKD & 0 & 8 & \\
\hline Time to ESKD (months) & 0 & $30.00 \pm 14.34$ & \\
\hline
\end{tabular}




\section{Gene Mutations Detected In Four Genes}

The overall detection rate of causal and putative causal mutations in children with SRNS was 27/70(38.57\%): 15(21.43\%) carried the NPHS2 p.V260E mutation in the homozygous state and $12(17.14 \%)$ SRNS cases carried a pathogenic mutation in the heterozygous state in genes (INF2, CD2AP, and TRPC6) known to have AD inheritance mode. Mutations in the NPHS2 (15/70, 21.13\%) gene were most common, followed by mutations in INF2 (8/70,11.43\%), CD2AP $(3 / 70,4.29 \%)$ and $\operatorname{TRPC6}(1 / 70,1.43 \%)$.

NPHS2 p.V260E homozygosity was specifically associated with biopsy-proven FSGS, accounting for $23.81 \%$ of Black children (15 of 63 ) with SR-FSGS but was present in none of the Indian children (0/7). In the heterozygous state, NPHS2 p.V260E was present in one of 206 (MAF=0.24\%) Black healthy controls (gnomAD allele frequency- 0.00013). WES was performed on seven Indian and 49 Black SRNS cases; ten genes implicated in monogenic SRNS in the SRNS children were interrogated. Autosomal dominant putative causal mutations are shown in Table 2. For the INF2 gene mutations, eight Black SRNS children carried the INF2 p.P516L (c.1547C>T; p.Pro516Leu) variant in the heterozygote state; this variant was absent in controls. Whole exome sequencing of 100 Black South Africans found the frequency of INF2 to be 0.03 (personal communication from Dr. M. Ramsay, University of Witwatersrand, South Africa). Assuming that the population frequency is $3 \%$, the probability that 8 or more out of 49 Black SRNS with WES data carry the INF2 p.P516L variant by random chance is $1.4 \times 10^{-5}$; however, more population typing will be required to get a robust estimate of the population frequency of this African-specific variant. With a Bonferroni correction for 10 genes tested, $\mathrm{p}=1.4 \times 10^{-4}$. The three Black children with SR-FSGS with mutations of the $C D 2 A P$ gene were carriers of the p.K633R mutation. A novel mutation, p.G162V in the TRPC6 gene, predicted to be 'possibly damaging' by PolyPhen was identified in one Indian child with SRFSGS and was absent in the controls.

Table 2

Description of variants identified in children with steroid resistant nephrotic syndrome

\begin{tabular}{|c|c|c|c|c|c|c|c|}
\hline \multirow{2}{*}{$\begin{array}{l}\text { Gene, Amino acid } \\
\text { change }\end{array}$} & \multirow{2}{*}{$\begin{array}{l}\text { Nucleotide } \\
\text { change }\end{array}$} & \multirow[t]{2}{*}{ RS number } & \multicolumn{2}{|l|}{ Prediction } & \multirow{2}{*}{$\begin{array}{l}\text { MAF } \\
\text { according } \\
\text { to } \\
\text { GenomAD }\end{array}$} & \multirow{2}{*}{$\begin{array}{l}\text { Prevalence in } \\
\text { control population }\end{array}$} & \multirow{2}{*}{$\begin{array}{l}\text { Reference } \\
\text { PMID or ClinVar ID }\end{array}$} \\
\hline & & & PolyPhen-2 & SIFT & & & \\
\hline \multicolumn{8}{|c|}{ Known causal variants } \\
\hline $\begin{array}{l}\text { NPHS2 } \\
\text { V260E }\end{array}$ & $\begin{array}{l}\text { c. } 3032- \\
21 A>T\end{array}$ & 775006954 & $\begin{array}{l}\text { Probably } \\
\text { Damaging }\end{array}$ & Damaging & 0.00013 & 1 & $\begin{array}{l}\text { PMID: } \\
\text { 25349199; PMID:28658201; } \\
\text { PMID: } 26420286\end{array}$ \\
\hline \multirow{3}{*}{ V260E } & & & & & & & $\begin{array}{l}\text { PMID:23595123; } \\
\text { PMID:22565185; PMID:21415313 }\end{array}$ \\
\hline & & & & & & & $\begin{array}{l}\text { PMID:20947785; } \\
\text { PMID:15253708; PMID:14675423 }\end{array}$ \\
\hline & & & & & & & $\begin{array}{l}\text { PMID:30450462; } \\
\text { PMID:31754646; PMID:26211502 }\end{array}$ \\
\hline \multicolumn{8}{|c|}{ Putative causal variants } \\
\hline $\begin{array}{l}C D 2 A P \\
\mathrm{~K} 633 \mathrm{R}\end{array}$ & c. $1898 \mathrm{~A}>\mathrm{G}$ & 116754410 & $\begin{array}{l}\text { Probably } \\
\text { Damaging }\end{array}$ & Damaging & 0.00755 & 0 & $\begin{array}{l}\text { RCV000398184.1; } \\
\text { RCV000250382.1 }\end{array}$ \\
\hline $\begin{array}{l}\text { TRPC6 } \\
\text { G162V }\end{array}$ & c. $485 \mathrm{G}>\mathrm{T}$ & Novel & $\begin{array}{l}\text { Probably } \\
\text { Damaging }\end{array}$ & Damaging & $\begin{array}{l}\text { Not } \\
\text { reported }\end{array}$ & 0 & Present study \\
\hline $\begin{array}{l}\text { INF2 } \\
\text { P516L }\end{array}$ & c. $1547 \mathrm{C}>\mathrm{T}$ & 111589086 & $\begin{array}{l}\text { Probably } \\
\text { Damaging }\end{array}$ & Damaging & 0.00739 & 0 & RCV000591895.2 \\
\hline \multicolumn{8}{|c|}{ Novel non-causal variants } \\
\hline $\begin{array}{l}\text { INF2 } \\
\text { S409T }\end{array}$ & c. $1226 \mathrm{G}>\mathrm{C}$ & Novel & Benign & Tolerated & $\begin{array}{l}\text { Not } \\
\text { reported }\end{array}$ & 0 & Present study \\
\hline $\begin{array}{l}\text { PLCE1 } \\
\text { A757E }\end{array}$ & & Novel & Benign & Tolerated & $\begin{array}{l}\text { Not } \\
\text { reported }\end{array}$ & 0 & Present study \\
\hline $\begin{array}{l}\text { ACTN4 } \\
\text { A58A }\end{array}$ & c. $174 \mathrm{C}>\mathrm{T}$ & Novel & N/A & N/A & $\begin{array}{l}\text { Not } \\
\text { reported }\end{array}$ & 0 & Present study \\
\hline
\end{tabular}

No pathogenic mutations were identified in NPHS1, WT1, LAMB2, PLCE1, MYO1E and ACTN4. However, we report four novel variants in INF2, PLCE1, ACTN4 and TRPC6 (Table 2). 


\section{Genotype-phenotype Associations}

Cases with causal or putative pathogenic mutations in the homozygous or heterozygous state, respectively, had a histology of FSGS and none responded to first-line corticosteroid therapy (Table 3). As shown in Figure 2, age-of-onset was younger in children homozygous for NPHS2 p.V260E compared to those carrying heterozygous mutations (mean 98.07; range 62-141 months $v s$. mean 156; range 119-202 months, respectively) ( $p=0.03$ ). Among the 12 children carrying heterozygous mutations, seven were treated with 2nd line immunosuppressive therapy. Partial remission with 2nd line immunosuppression was achieved for the child EN300232 heterozygous for TRPC6 p.G162V and for child EN300052 heterozygous for CD2AP p.K633R; a second child with CD2AP p.K633R did not respond to 2 nd line treatment. Five of 15 children (30\%) with the NPHS2 p.V260E progressed to ESKD whereas none of the children with INF2 p.P516L progressed to ESKD over the mean 25.11 months of follow-up. 
Table 3

Clinical characteristics of steroid-resistant nephrotic syndrome children with identified mutations

\begin{tabular}{|c|c|c|c|c|c|c|c|c|c|c|c|}
\hline $\begin{array}{l}\text { Patient } \\
\text { No. }\end{array}$ & Sex & Ethnicity & Gene & Mutation & $\begin{array}{l}\text { Age at } \\
\text { onset } \\
\text { (Months) }\end{array}$ & $\begin{array}{l}\text { Dipstick } \\
\text { analysis }\end{array}$ & $\begin{array}{l}\text { Serum } \\
\text { albumin }\end{array}$ & Histology & $\begin{array}{l}\text { Response to } \\
\text { corticosteroids } \\
\text { (1 st line) }\end{array}$ & $\begin{array}{l}\text { Response to } \\
\text { immunosuppressants } \\
\text { (2nd line) }\end{array}$ & ESK \\
\hline EN300027 & Male & Black & NPHS2 & $\begin{array}{l}\text { V260E } \\
\text { (hom) }\end{array}$ & 86 & $3+$ & 25 & FSGS & No response & No response & YES \\
\hline EN300041 & Female & Black & NPHS2 & $\begin{array}{l}\text { V260E } \\
\text { (hom) }\end{array}$ & 80 & $2+$ & 21 & FSGS & No response & Not given & NO \\
\hline EN300044 & Female & Black & NPHS2 & $\begin{array}{l}\text { V260E } \\
\text { (hom) }\end{array}$ & 127 & $2+$ & 29 & FSGS & No response & No response & YES \\
\hline EN300045 & Female & Black & NPHS2 & $\begin{array}{l}\text { V260E } \\
\text { (hom) }\end{array}$ & 62 & $3+$ & 19 & FSGS & No response & Not given & NO \\
\hline EN300047 & Female & Black & NPHS2 & $\begin{array}{l}\text { V260E } \\
\text { (hom) }\end{array}$ & 90 & $2+$ & 22 & FSGS & No response & Not given & NO \\
\hline EN300048 & Female & Black & NPHS2 & $\begin{array}{l}\text { V260E } \\
\text { (hom) }\end{array}$ & 157 & $1+$ & 39 & FSGS & No response & No response & YES \\
\hline EN300050 & Male & Black & NPHS2 & $\begin{array}{l}\text { V260E } \\
\text { (hom) }\end{array}$ & 24 & $2+$ & 25 & FSGS & No response & Not given & NO \\
\hline EN300055 & Female & Black & NPHS2 & $\begin{array}{l}\text { V260E } \\
\text { (hom) }\end{array}$ & 25 & $2+$ & 18 & FSGS & No response & Not given & NO \\
\hline EN300057 & Female & Black & NPHS2 & $\begin{array}{l}\text { V260E } \\
\text { (hom) }\end{array}$ & 178 & $3+$ & 19 & FSGS & No response & No response & NO \\
\hline EN300072 & Female & Black & NPHS2 & $\begin{array}{l}\text { V260E } \\
\text { (hom) }\end{array}$ & 101 & $3+$ & 15 & FSGS & No response & No response & NO \\
\hline EN300139 & Female & Black & NPHS2 & $\begin{array}{l}\text { V260E } \\
\text { (hom) }\end{array}$ & 64 & $2+$ & 16 & FSGS & No response & Not given & NO \\
\hline EN300305 & Female & Black & NPHS2 & $\begin{array}{l}\text { V260E } \\
\text { (hom) }\end{array}$ & 61 & $2+$ & 28 & FSGS & No response & No response & YES \\
\hline EN300310 & Female & Black & NPHS2 & $\begin{array}{l}\text { V260E } \\
\text { (hom) }\end{array}$ & 141 & $2+$ & 19 & FSGS & No response & No response & YES \\
\hline EN300329 & Male & Black & NPHS2 & $\begin{array}{l}\text { V260E } \\
\text { (hom) }\end{array}$ & 99 & $3+$ & 18 & FSGS & No response & No response & NO \\
\hline EN300355 & Male & Black & NPHS2 & $\begin{array}{l}\text { V260E } \\
\text { (hom) }\end{array}$ & 176 & $3+$ & 23 & FSGS & No response & Not given & NO \\
\hline EN300144 & Male & Black & INF2 & $\begin{array}{l}\text { P516L } \\
\text { (het) }\end{array}$ & 81 & $4+$ & 11 & FSGS & No response & No response & NO \\
\hline EN300022 & Male & Black & INF2 & $\begin{array}{l}\text { P516L } \\
\text { (het) }\end{array}$ & 131 & $3+$ & 26 & FSGS & No response & Not given & NO \\
\hline EN300156 & Male & Black & INF2 & $\begin{array}{l}\text { P516L } \\
\text { (het) }\end{array}$ & 167 & $1+$ & 45 & FSGS & No response & No response & NO \\
\hline EN300157 & Female & Black & INF2 & $\begin{array}{l}\text { P516L } \\
\text { (het) }\end{array}$ & 220 & $1+$ & 35 & FSGS & No response & No response & NO \\
\hline EN300312 & Female & Black & INF2 & $\begin{array}{l}\text { P516L } \\
\text { (het) }\end{array}$ & 115 & $1+$ & 72 & FSGS & No response & Not given & NO \\
\hline EN300313 & Male & Black & INF2 & $\begin{array}{l}\text { P516L } \\
\text { (het) }\end{array}$ & 211 & $1+$ & 17 & FSGS & No response & Not given & NO \\
\hline EN300345 & Male & Black & INF2 & $\begin{array}{l}\text { P516L } \\
\text { (het) }\end{array}$ & 168 & $2+$ & 43 & FSGS & No response & No response & NO \\
\hline EN300363 & Female & Black & INF2 & $\begin{array}{l}\text { P516L } \\
\text { (het) }\end{array}$ & 169 & $3+$ & & FSGS & No response & Not given & NO \\
\hline EN300052 & Female & Black & $C D 2 A P$ & $\begin{array}{l}\text { K633R } \\
\text { (het) }\end{array}$ & 62 & $4+$ & 18 & FSGS & No response & Partial remission & NO \\
\hline EN300302 & Female & Black & $C D 2 A P$ & $\begin{array}{l}\text { K633R } \\
\text { (het) }\end{array}$ & 175 & $2+$ & 21 & FSGS & No response & No response & NO \\
\hline EN300322 & Male & Black & $C D 2 A P$ & $\begin{array}{l}\text { K633R } \\
\text { (het) }\end{array}$ & 165 & $2+$ & 35 & FSGS & No response & Not given & NO \\
\hline
\end{tabular}




\begin{tabular}{|c|c|c|c|c|c|c|c|c|c|c|c|}
\hline $\begin{array}{l}\text { Patient } \\
\text { No. }\end{array}$ & Sex & Ethnicity & Gene & Mutation & $\begin{array}{l}\text { Age at } \\
\text { onset } \\
\text { (Months) }\end{array}$ & $\begin{array}{l}\text { Dipstick } \\
\text { analysis }\end{array}$ & $\begin{array}{l}\text { Serum } \\
\text { albumin }\end{array}$ & Histology & $\begin{array}{l}\text { Response to } \\
\text { corticosteroids } \\
\text { (1st line) }\end{array}$ & $\begin{array}{l}\text { Response to } \\
\text { immunosuppressants } \\
\text { (2nd line) }\end{array}$ & ESK \\
\hline EN300232 & Male & Indian & TRPC6 & $\begin{array}{l}\text { G162V } \\
\text { (het) }\end{array}$ & 216 & $2+$ & 38 & FSGS & No response & Partial remission & NO \\
\hline
\end{tabular}

\section{Differences in clinical features between children with mutations and without detected mutations}

Clinical and laboratory data of children with monogenic cause of FSGS vs no mutations are presented in Table 4. Although the mean age at onset of proteinuria was lower in the group with mutations (mean 124.10 months; $95 \% \mathrm{Cl}$ : 101.50-146.70) than in children with no mutations (mean 138.70 ; $95 \% \mathrm{Cl}$ : 124.30-153.00 months) this was not statistically significant $(p=0.37)$. No significant difference was noted in the clinical presentation (oedema and blood pressure), proteinuria, serum albumin and cholesterol levels between the groups. Children with mutations presented with a higher serum creatinine (mean 94.85; $95 \% \mathrm{Cl}: 25.45-164.2 \mathrm{umol} / \mathrm{l}$ ) than children with no mutation (mean 43.36; $95 \% \mathrm{Cl}$ : 31.52-55.19 umol/I) although this was not statistically significant ( $p=$ 0.17). Nine (20.45\%) children with non-genetic forms of SRNS achieved complete remission and six (13.64\%) were in partial remission following treatment with additional immunosuppressants compared with none (100\%) of the children with genetic forms of SRNS. The proportion of patients who progressed ESKD was higher in children with genetic mutations than in children without genetic mutations, albeit not statistically significant $(p=0.13)$. The duration from first presentation and progression to ESKD was significantly longer in children with no genetic mutations (mean 47.00; $95 \%$ Cl: $37.06-56.94$ months) than in children with genetic mutations (mean 19.80; 95\% Cl: 16.97-22.63 months) $(p=0.01)$.

Table 4

Genotype-phenotype correlations in paediatric patients with steroid-resistant nephrotic syndrome.

\begin{tabular}{|c|c|c|c|}
\hline Phenotype & Positive mutation detected $(n=27)$ & $\begin{array}{l}\text { No mutation detected } \\
(n=43)\end{array}$ & $\begin{array}{l}\text { Mutation vs no mutation } \\
p \text { value }\end{array}$ \\
\hline Sex & & & 0.33 \\
\hline Male & $11(40.74 \%)$ & $23(53.48 \%)$ & \\
\hline Female & $16(59.26 \%)$ & $20(46.51 \%)$ & \\
\hline Ethnicity & & & 0.24 \\
\hline Black & $26(96.30 \%)$ & $37(86.04 \%)$ & \\
\hline Indian & $1(3.70 \%)$ & $6(13.95 \%)$ & \\
\hline Age of onset (months) & $124.10 \pm 57.10$ & $138.69 \pm 47.09$ & 0.37 \\
\hline Presence of oedema at first presentation & $15(55.56 \%)$ & $16(37.21 \%)$ & 0.12 \\
\hline Hypertension & & & 0.50 \\
\hline Stage 1 & $8(29.63 \%)$ & $13(29.55 \%)$ & \\
\hline Stage 2 & $8(29.63 \%)$ & $7(15.91 \%)$ & \\
\hline Proteinuria & $3.79 \pm 4.21$ & $3.65 \pm 4.51$ & 0.87 \\
\hline Serum Albumin $(g / l)$ & $26.81 \pm 12.93$ & $29.41 \pm 10.14$ & 0.13 \\
\hline Creatinine (umol/l) & $94.85 \pm 71.80$ & $43.36 \pm 36.51$ & 0.17 \\
\hline Cholesterol (mmol/l) & $8.01 \pm 3.16$ & $7.15 \pm 3.43$ & 0.90 \\
\hline Kidney biopsy & & & 0.28 \\
\hline FSGS & $27(100 \%)$ & $40(93.02 \%)$ & \\
\hline MCD & 0 & $3(6.98 \%)$ & \\
\hline ESKD & $5(18.52 \%)$ & $3(6.98 \%)$ & 0.13 \\
\hline Time at ESKD (months) & $19.80 \pm 2.28$ & $47.00 \pm 4.00$ & 0.01 \\
\hline Recurrence after kidney transplant $(n=3)$ & 0 & 0 & \\
\hline
\end{tabular}

\section{Discussion}

The high rate of steroid resistance in Black South African children compared to other racial groups prompted the need to further investigate the genetic basis for this racial disparity. Asharam et al. identified the NPHS2 p.V260E mutation as a frequent cause of AR SR-FSGS in Black children with NS, potentially 
sparing these children the use of steroids and other immunosuppressive drugs as well as the need to undergo kidney biopsy ${ }^{[18,32]}$. As the NPHS2 p.V260E is not infrequent in the general South African population (MAF 0.2-1\%) and explains approximately 30\% of SR-FSGS in Black South African children; therefore, we first genotyped all cases and controls for the p.V260E mutation.

In this study, we detected NPHS2 p.V260E homozygosity in $21.43 \%$ of Black children with a general diagnosis of SRNS and $23.81 \%$ with a specific diagnosis of SR-FSGS. The detection rate of $23.81 \%$ for the homozygous p.V260E mutation-specific to SR-FSGS in our study was lower than the two previous reports from South Africa that reports rates of 33\% (Asharam et al., 2018) and 50\% [32]. The NPHS2 gene, encoding podocin, is an integral structural protein of the podocyte. Although the NPHS2 p.V260E variant likely arose in Africans, it was first identified in several consanguineous families from the previous Omani empire $^{[18,41,42]}$. Like the European founder variant p.R138Q, the p.V260E variant disrupts the transport of the modified podocin protein from the endoplasmic reticulum to the plasma membrane ${ }^{[43-45]}$

A variable and earlier age of onset (range 24 to 178 months) in children was observed in children homozygous for the NPHS2 p.V260E mutation. In an earlier report, Black SR-FSGS cases homozygous for p.V260E had an earlier age of onset compared to SRNS cases homozygous for the p.V260 reference allele (median onset of age, 34 months vs. 78 months, $p=0.01)^{[18]}$. The findings of our study in children carrying the p.V260E mutation highlight the variability of the phenotype seen in SR-FSGS. That said, it is important to consider NPHS2 p.V260E mutation as a cause for SRNS in all paediatric age groups. In contrast to the findings in SRNS, we did not detect any homozygous or compound heterozygous mutations for NPHS2 p.V260E among patients with SSNS, consistent with previously published reports showing that this mutation is specifically associated with SR-FSGS ${ }^{[18,32,46-48]}$.

NPHS2-mediated disease is resistant to corticosteroids and other immunosuppressants ${ }^{[21,42,46,49]}$. Additionally, several studies have highlighted a high risk of progression to ESKD in monogenic SRNS, with many patients requiring kidney transplantation and a low risk of disease reoccurrence post-transplant when a genetic aetiology has been confirmed ${ }^{[19,42,50-53]}$. In keeping with published reports, none of the children in our study homozygous for the NPHS2 p.V260E variant responded to any second-line treatment. We also found that individuals who did not have the NPHS2 p.V260E variant progressed more slowly to ESKD. Moreover, three of the five children that progressed to ESKD underwent a kidney transplant and no disease recurrence occurred. Screening for the NPHS2 p.V260E mutation has the potential to provide a precision diagnosis of SR-FSGS thereby informing the differential diagnosis, prognosis, and treatment in 20$30 \%$ of Black African children presenting with NS.

In those children lacking the NPHS2 p.V260E mutations, we observed 12 children with sporadic SR-FSGS carrying putative causal mutations in the following AD genes [INF2 $(\mathrm{n}=8), \operatorname{CD} 2 A P(\mathrm{n}=3)$ and TRPC6 $(\mathrm{n}=1)]$. Autosomal dominant SRNS typically presents later in life, in adolescence or adulthood, and has significant phenotypic variability ${ }^{[20]}$. In our study, a later age of onset in children carrying an AD mutation (range 62-220 months) was observed when compared to AR mutation (range 24-178 months). Two children carrying an AD mutation in CD2AP and TRPC6 were in partial remission following treatment with calcineurin inhibitors in contrast to all 15 children with an NPHS2 mutation who did not respond to any additional immunosuppressants.

Recently, mutations in INF2 were reported as the most common cause of adolescent-onset autosomal dominant SR-FSGS ${ }^{[54,55]}$. Only three INF2 mutations have been previously reported in a total of 436 sporadic SR-FSGS cases ( $<1 \%)$, all of which occur in the N-terminus ${ }^{[54-57]}$. In this study, a putative causal variant INF2 p.P516L in the INF2 gene was present in the heterozygote state in eight Black SRNS cases with biopsy-proven FSGS with an age of onset ranging from 6 to 18 years. The clinical characteristics of the children carrying the p.P516L variant in this study are in corroboration with previous reports which show INF2 mutations as a common cause of FSGS with incomplete penetrance and variable age of onset ranging from $10-70$ years ${ }^{[27,54,57]}$. The finding that $16 \%$ of Black children with SRNS undergoing WES carried the mutation compared to $3 \%$ of the South African population indicates that this predicted pathogenic variant merits further investigation to determine penetrance and causality.

Despite the clear association of $C D 2 A P$ defects with a glomerular pathology suggestive of idiopathic FSGS in animal models, data is sparse in humans ${ }^{[58,59]}$. In our study, we identified three Black children with SR-FSGS harbouring a heterozygous putative causal mutation (p.K633R) in the CD2AP gene. The first report by Kim et al. described one heterozygous nucleotide variant resulting in an aberrant $C D 2 A P$ splicing in two patients with idiopathic FSGS ${ }^{[58]}$. More recently, Asharam et al. reported on a heterozygote $C D 2 A P$ p.K346N variant in an Indian child with SR-FSGS ${ }^{[18]}$. Notably, the only child with $C D 2 A P$-associated nephropathy was in partial remission at last hospital visit after treatment with cyclosporin $A$. This treatment reduced the proteinuria by $\sim 50 \%$, whilst the remaining two patients failed to respond. A case report by Tsvetkov et al. showed that ciclosporin A is a treatment option for $C D 2 A P$-associated nephropathy ${ }^{[60]}$. However, further studies and clinical trials are required on the use of cyclosporin $A$ as a therapeutic option for patients with $C D 2 A P$-associated nephropathy.

The TRPC6 gene encodes the transient receptor potential cation channel, which is located on the podocyte membrane where together with podocin, it regulates mechano-sensation at the slit diaphragm ${ }^{[61]}$. autosomal dominant SR-FSGS, with variable age of onset from early childhood through adulthood ${ }^{[62-}$ 65]. In our study, we report a novel putative causal mutation, TRPC6 p.G162V in one SRNS Indian child with biopsy-proven FSGS with an age of onset of 18 years. The clinical phenotype of this patient improved after treatment with calcineurin inhibitors (tacrolimus). At last hospital visit, the patient was in partial remission. Our findings together with previous reports suggest that calcineurin inhibitors could open up new avenues on the treatment of TRPC6-associated FSGS $^{[65,66]}$.

This study has several limitations. Family members were not available for segregation studies to determine the penetrance of the heterozygous variants. Due to the small number of controls typed for INF2 P.516L, and the limited number typed for the population frequency estimate of this variant the statistical significance of its association with disease is not clearly established. Causality of INF2 p.P516L, CD2AP p.K346N, and TRC6 p.G162V has not been demonstrated in animal models or in vitro cell studies. 
This is the largest study in a paediatric South African population to perform sequence analysis of ten candidate genes (NPHS1, NPHS2, WT1, LAMB2, ACTN4, TRPC6, INF2, CD2AP, PLCE1, MYO1E) associated with SR-FSGS. We have confirmed that the NPHS2 p.V260E mutation is a prevalent cause of SR-FSGS among Black South African children occurring in $23.81 \%$ of children with SRNS. Given the large number of children with NPHS2 mutations, sufficiently powered clinical trials may be possible on testing different treatment therapies on these children and comparing outcomes. We also report putative causal missense variants in INF2, CD2AP and TRPC6. Screening all Black African children with NS for NPHS2 p.V260E and possibly INF2 p.P516L, if causality is shown, has the potential to be highly predictive of a diagnosis of SR-FSGS and multi-resistant forms of NS. Detection of pathogenic mutations will obviate the need for a kidney biopsy and the use of additional immunosuppressant drugs thus avoiding complications of an invasive procedure and the serious adverse effects of treatment. Precision genetic diagnosis will enable clinicians to provide genetic counselling, detect carriers, and propose prenatal diagnosis to couples at risk.

\section{List Of Abbreviations}

AD: autosomal dominant; AR: autosomal recessive; CKD: chronic kidney disease; ESKD: end stage kidney disease; FSGS: focal segmental glomerulosclerosis; MCD: minimal change disease; NS: nephrotic syndrome; SRNS: steroid resistant nephrotic syndrome; SSNS: steroid sensitive nephrotic syndrome; WES: whole exome sequencing

\section{Declarations}

\section{Acknowledgements}

The authors thank Inkosi Albert Luthuli Central Hospital and all the patients who consented permission to participate in the study, the Optics and Imaging Centre, DDMRI, College of Health Sciences and the National Cancer Institue and the Frederick National Laboratory for Cancer Research, United States of America, where the study was conducted. We thank Elizabeth Binns-Roemer (FNLCR) and Victor D. David (NCl) for excellent technical assistance.

Funding: Funding was received from the College of Health Sciences, University of KwaZulu-Natal, and National Institute of Health (NIH), United States of America. CAW was funded in part with federal funds from the National Cancer Institute, National Institutes of Health, under contract HHSN26120080001E and supported in part by the Intramural Research Program of the NIH, National Cancer Institute, Center for Cancer Research. The content of this publication does not necessarily reflect the views or policies of the National Institutes of Health (USA).

Conflicts of interest/Competing interests: The authors have no relevant financial or non-financial interests to disclose.

\section{Availability of data and material: N/A}

\section{Code availability: N/A}

Authors' contributions: All authors contributed to the study conception and design. Material preparation, data collection and analysis were performed by Louansha Nandlal, Rajendra Bhimma, Cheryl Winkler, Sungkweon Cho and George W. Nelson. The first draft of the manuscript was written by Louansha Nandlal, and all authors commented on previous versions of the manuscript. All authors read and approved the final manuscript.

Ethics approval: This study protocol was reviewed and approved by Biomedical Research Ethics Committee of the University of KwaZulu-Natal and Department of Health, KwaZulu-Natal, South Africa, approval number BE374/17.

Consent to participate: Written informed consent was obtained from the parent/guardian of each child and children over seven years provided assent for participation in the study.

Consent for publication: All authors named consent to the publication of this manuscript.

\section{References}

1. Eddy AA, Symons JM (2003) Nephrotic syndrome in childhood The Lancet. 362(9384):629-39. doi: 10.1016/S0140-6736(03)14184-0

2. Sinha A, Bagga A (2012) Nephrotic syndrome. The Indian Journal of Pediatrics 79(8):1045-1055. doi: 10.1007/s12098-012-0776-y

3. Yu Z, Ding J, Huang J, Yao Y, Xiao H, Zhang J et al (2005) Mutations in NPHS2 in sporadic steroid-resistant nephrotic syndrome in Chinese children. Nephrology Dialysis Transplantation 20(5):902-908. doi.org/10.1093/ndt/gfh769

4. Gipson DS, Massengill SF, Yao L, Nagaraj S, Smoyer WE, Mahan JD et al (2009) Management of childhood onset nephrotic syndrome. Pediatrics 124(2):747-757. doi: 10.1542/peds.2008-1559

5. Levey AS, Eckardt K-U, Dorman NM, Christiansen SL, Cheung M, Jadoul M et al (2020) Nomenclature for kidney function and disease: executive summary and glossary from a Kidney Disease: Improving Global Outcomes (KDIGO) consensus conference. Kidney Diseases. 6(5):309-17. doi.org/10.1159/000509359

6. Siji A, Karthik K, Pardeshi VC, Hari P, Vasudevan A (2018) Targeted gene panel for genetic testing of south Indian children with steroid resistant nephrotic syndrome. BMC Med Genet 19(1):200. doi: 10.1186/s12881-018-0714-6

7. Bircan Z, Yavuz Yilmaz A, Katar S, Vitrinel A, Yildirim M (2002) Childhood idiopathic nephrotic syndrome in Turkey. Pediatr Int 44(6):608-611. doi: 10.1046/j.1442-200x.2002.01628.x 
8. McKinney PA, Feltbower RG, Brocklebank JT, Fitzpatrick MM (2001) Time trends and ethnic patterns of childhood nephrotic syndrome in Yorkshire, UK. Pediatric Nephrology 16(12):1040-1044. doi: 10.1007/s004670100021

9. Mortazavi F, Khiavi YS (2011) Steroid response pattern and outcome of pediatric idiopathic nephrotic syndrome: a single-center experience in northwest Iran. Ther Clin Risk Manag 7:167. doi: 10.2147/TCRM.S19751

10. Kiffel J, Rahimzada Y, Trachtman H (2011) Focal segmental glomerulosclerosis and chronic kidney disease in pediatric patients. Advances in Chronic Kidney Disease 18(5):332-338

11. Chanchlani R, Parekh RS (2016) Ethnic differences in childhood nephrotic syndrome. Front Pead 4:39

12. Boyer O, Moulder JK, Somers MJ (2007) Focal and segmental glomerulosclerosis in children: a longitudinal assessment. Pediatric Nephrology 22(8):1159-1166

13. Sorof JM, Hawkins EP, Brewer ED, Boydstun II, Kale AS, Powell DR (1998) Age and ethnicity affect the risk and outcome of focal segmental glomerulosclerosis. Pediatric Nephrology 12(9):764-768

14. Adhikari M, Bhimma R, Coovadia H (2001) Focal segmental glomerulosclerosis in children from KwaZulu/Natal, South Africa. Clin Nephrol 55(1):16-24

15. Bhimma R, Coovadia HM, Adhikari M (1997) Nephrotic syndrome in South African children: changing perspectives over 20 years. Pediatric Nephrology 11(4):429-434

16. Coovadia H, Adhikari M, Morel-Maroger L (1979) Clinico-pathological features of the nephrotic syndrome in South African children. QJM: An International Journal of Medicine. 48(1):77-91

17. Abumregha O, Naicker E, Connolly C, Bhimma R (2020) Primary Nephrotic Syndrome In The New Millennium In Kwazulu-Natal, South Africa. Kidney International Reports 5(3):S233-S2S4

18. Asharam K, Bhimma R, David VA, Coovadia HM, Qulu WP, Naicker T et al (2018) NPHS2 V260E is a frequent cause of steroid-resistant Nephrotic syndrome in black south African children. Kidney International Reports. 3(6):1354-62

19. Bierzynska A, McCarthy HJ, Soderquest K, Sen ES, Colby E, Ding WY et al (2017) Genomic and clinical profiling of a national nephrotic syndrome cohort advocates a precision medicine approach to disease management. Kidney Int 91(4):937-947

20. Preston HMSRL (2017) Genetic testing in steroid-resistant nephrotic syndrome: why, who, when and how? Pediatric Nephrology 31(11):1802-1813

21. Brown EJ, Pollak MR, Barua M (2014) Genetic testing for nephrotic syndrome and FSGS in the era of next-generation sequencing. Kidney Int 85(5):10301038

22. Che R, Zhang A (2013) Mechanisms of glucocorticoid resistance in idiopathic nephrotic syndrome. Kidney and Blood Pressure Research 37(4-5):360378

23. Benoit G, Machuca E, Nevo F, Gribouval O, Lepage D, Antignac C (2010) Analysis of recessive CD2APand ACTN4 mutations in steroid-resistant nephrotic syndrome. Pediatric Nephrology 25(3):445-451

24. Boyer O, Benoit G, Gribouval O, Nevo F, Pawtowski A, Bilge I et al (2010) Mutational analysis of the PLCE1 gene in steroid resistant nephrotic syndrome. J Med Genet 47(7):445-452

25. Kaplan JM, Kim SH, North KN, Rennke H, Correia LA, Tong H-Q et al (2000) Mutations in ACTN4, encoding a-actinin-4, cause familial focal segmental glomerulosclerosis. Nat Genet 24(3):251

26. Santín S, Bullich G, Tazón-Vega B, García-Maset R, Giménez I, Silva I et al (2011) Clinical utility of genetic testing in children and adults with steroidresistant nephrotic syndrome. Clin J Am Soc Nephrol 6(5):1139-1148

27. Brown EJ, Schlöndorff JS, Becker DJ, Tsukaguchi H, Tonna SJ, Uscinski AL et al (2010) Mutations in the formin gene INF2 cause focal segmental glomerulosclerosis. Nat Genet 42(1):72

28. Löwik M, Groenen P, Levtchenko E, Monnens L, Van Den Heuvel L (2009) Molecular genetic analysis of podocyte genes in focal segmental glomerulosclerosis-a review. Eur J Pediatrics 168(11):1291

29. Zenker M, Machuca E, Antignac C (2009) Genetics of nephrotic syndrome: new insights into molecules acting at the glomerular filtration barrier. J Mol Med 87(9):849

30. Bińczak-Kuleta A, Rubik J, Litwin M, Ryder M, Lewandowska K, Taryma-Leśniak O et al (2014) Retrospective mutational analysis of NPHS1, NPHS2, WT1 and $\angle A M B 2$ in children with steroid-resistant focal segmental glomerulosclerosis-a single-centre experience. Bosnian Journal of Basic Medical Sciences 14(2):89

31. Anigilaje EA, Olutola A (2019) Prospects of genetic testing for steroid-resistant nephrotic syndrome in Nigerian children: a narrative review of challenges and opportunities. International Journal of Nephrology and Renovascular Disease 12:119

32. Govender MA, Fabian J, Gottlich E, Levy C, Moonsamy G, Maher H et al (2019) The podocin V260E mutation predicts steroid resistant nephrotic syndrome in black South African children with focal segmental glomerulosclerosis. Communications biology 2(1):1-7

33. National High Blood Pressure Education Program (2005) The fourth report on the diagnosis, evaluation, and treatment of high blood pressure in children and adolescents. US Department of Health and Human Services, National Institutes of Health

34. MDCalc, Revised Schwartz Equation for Glomerular Filtration Rate (GFR) (2009) 2009 [cited 201915 October]. Available from: https://www.mdcalc.com/revised-schwartz-equation-glomerular-filtration-rate-gfr-2009\#use-cases

35. Schwartz GJ, Munoz A, Schneider MF, Mak RH, Kaskel F, Warady BA et al (2009) New equations to estimate GFR in children with CKD. J Am Soc Nephrol 20(3):629-637 
36. Kellum JA, Lameire N, Aspelin P, Barsoum RS, Burdmann EA, Goldstein SL et al (2012) Kidney disease: improving global outcomes (KDIGO) acute kidney injury work group. KDIGO clinical practice guideline for acute kidney injury. Kidney International Supplements 2(1):1-138

37. MacArthur D, Manolio T, Dimmock D, Rehm H, Shendure J, Abecasis $\mathrm{G}$ et al (2014) Guidelines for investigating causality of sequence variants in human disease. Nature 508(7497):469-476

38. Yang Y, Muzny DM, Reid JG, Bainbridge MN, Willis A, Ward PA et al (2013) Clinical whole-exome sequencing for the diagnosis of mendelian disorders. N Engl J Med 369(16):1502-1511

39. Gee HY, Cachau R, Choi JM, Park D, Jee SH, Ryu S et al (2019) Contribution of SLC22A12 on hypouricemia and its clinical significance for screening purposes. Sci Rep 9(1):1-9

40. Sperling $O$ (2006) Hereditary renal hypouricemia. Mol Genet Metab 89(1-2):14-18

41. Machuca E, Benoit G, Nevo F, Tête M-J, Gribouval O, Pawtowski A et al (2010) Genotype-phenotype correlations in non-Finnish congenital nephrotic syndrome. J Am Soc Nephrol 21(7):1209-1217

42. Weber S, Gribouval O, Esquivel EL, Morinière V, Tête M-J, Legendre C et al (2004) NPHS2 mutation analysis shows genetic heterogeneityof steroid-resistant nephrotic syndrome and lowpost-transplant recurrence. Kidney Int 66(2):571-579

43. Machuca E, Hummel A, Nevo F, Dantal J, Martinez F, Al-Sabban E et al (2009) Clinical and epidemiological assessment of steroid-resistant nephrotic syndrome associated with the NPHS2 R229Q variant. Kidney International 75(7):727-735

44. Jain V, Feehally J, Jones G, Robertson L, Nair D, Vasudevan P (2014) Steroid-resistant nephrotic syndrome with mutations in NPHS2 (podocin): report from a three-generation family. Clinical Kidney Journal 7(3):303-305

45. Roselli S, Moutkine I, Gribouval O, Benmerah A, Antignac C (2004) Plasma membrane targeting of podocin through the classical exocytic pathway: effect of NPHS2 mutations. Traffic 5(1):37-44

46. Ruf RG, Lichtenberger A, Karle SM, Haas JP, Anacleto FE, Schultheiss M et al (2004) Patients with mutations in NPHS2 (podocin) do not respond to standard steroid treatment of nephrotic syndrome. J Am Soc Nephrol 15(3):722-732

47. Caridi G, Bertelli R, Di Duca M, Dagnino M, Emma F, Muda AO et al (2003) Broadening the spectrum of diseases related to podocin mutations. J Am Soc Nephrol 14(5):1278-1286

48. Frishberg Y, Rinat C, Megged O, Shapira E, Feinstein S, Raas-Rothschild A (2002) Mutations in NPHS2 encoding podocin are a prevalent cause of steroidresistant nephrotic syndrome among Israeli-Arab children. J Am Soc Nephrol 13(2):400-405

49. Boute N, Gribouval O, Roselli S, Benessy F, Lee H, Fuchshuber A et al (2000) NPHS2, encoding the glomerular protein podocin, is mutated in autosomal recessive steroid-resistant nephrotic syndrome. Nat Genet 24(4):349

50. Maas RJ, Deegens JK, van den Brand JA, Cornelissen EA, Wetzels JF (2013) A retrospective study of focal segmental glomerulosclerosis: clinical criteria can identify patients at high risk for recurrent disease after first renal transplantation. BMC Nephrol 14(1):47

51. Weber S, Tönshoff B (2005) Recurrence of focal-segmental glomerulosclerosis in children after renal transplantation: clinical and genetic aspects. Transplantation 80(1):128-134

52. Santín S, Tazón-Vega B, Silva I, Cobo M, Giménez I, Ruíz P et al (2011) Clinical value of NPHS2 analysis in early-and adult-onset steroid-resistant nephrotic syndrome. Clinical Journal of the American Society of Nephrology 6(2):344-354

53. Giglio S, Provenzano A, Mazzinghi B, Becherucci F, Giunti L, Sansavini G et al (2015) Heterogeneous genetic alterations in sporadic nephrotic syndrome associate with resistance to immunosuppression. J Am Soc Nephrol 26(1):230-236

54. Gbadegesin RA, Lavin PJ, Hall G, Bartkowiak B, Homstad A, Jiang R et al (2012) Inverted formin 2 mutations with variable expression in patients with sporadic and hereditary focal and segmental glomerulosclerosis. Kidney Int 81(1):94-99

55. Barua M, Brown EJ, Charoonratana VT, Genovese G, Sun H, Pollak MR (2013) Mutations in the INF2 gene account for a significant proportion of familial but not sporadic focal and segmental glomerulosclerosis. Kidney International 83(2):316-322

56. Gbadegesin RA, Lavin PJ, Hall G, Bartkowiak B, Homstad A, Jiang R et al (2012) Inverted formin 2 mutations with variable expression in patients with sporadic and hereditary focal and segmental glomerulosclerosis. Kidney Int 81(1):94-99

57. Lipska BS, latropoulos P, Maranta R, Caridi G, Ozaltin F, Anarat A et al (2013) Genetic screening in adolescents with steroid-resistant nephrotic syndrome. Kidney International 84(1):206-213

58. Kim JM, Wu H, Green G, Winkler CA, Kopp JB, Miner JH, Unanue ER, Shaw AS (2003) CD2-associated protein haploinsufficiency is linked to glomerular disease susceptibility. Science 300(5623):1298-1300

59. Yu H, Artomov M, Brähler S, Stander MC, Shamsan G, Sampson MG et al (2016) A role for genetic susceptibility in sporadic focal segmental glomerulosclerosis. J Clin Investig 126(3):1067-1078

60. Tsvetkov D, Hohmann M, Anistan YM, Mannaa M, Harteneck C, Rudolph B, Gollasch M (2016) A CD2AP mutation associated with focal segmental glomerulosclerosis in young adulthood. Clinical Medicine Insights: Case Reports 9:30867

61. Hsu Y-J, Hoenderop JG, Bindels RJ (2007) TRP channels in kidney disease. Molecular Basis of Disease 1772(8):928-936

62. Winn MP, Conlon PJ, Lynn KL, Farrington MK, Creazzo T, Hawkins AF et al (2005) A mutation in the TRPC6 cation channel causes familial focal segmental glomerulosclerosis. Science 308(5729):1801-1804

63. Reiser J, Polu KR, Möller CC, Kenlan P, Altintas MM, Wei C et al (2005) TRPC6 is a glomerular slit diaphragm-associated channel required for normal renal function. Nature Genetics 37(7):739-744 
64. Zhu B, Chen N, Wang Z-h, Pan X-x, Ren H, Zhang W, Wei-ming W (2009) Identification and functional analysis of a novel TRPC6 mutation associated with late onset familial focal segmental glomerulosclerosis in Chinese patients. Mutation Research/Fundamental and Molecular Mechanisms of Mutagenesis 664(1-2):84-90

65. Gigante M, Caridi G, Montemurno E, Soccio M, d'Apolito M, Cerullo G et al (20111). TRPC6 mutations in children with steroid-resistant nephrotic syndrome and atypical phenotype. Clinical Journal of the American Society of Nephrology. 6(7):1626-34

66. Schlöndorff J, del Camino D, Carrasquillo R, Lacey V, Pollak MR (2009) TRPC6 mutations associated with focal segmental glomerulosclerosis cause constitutive activation of NFAT-dependent transcription. American Journal of Physiology-Cell Physiology 296(3):558-569

\section{Figures}

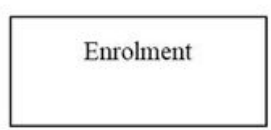

Participants genotyped

for NPHS2 p.V260E

Positive result for p.V260E

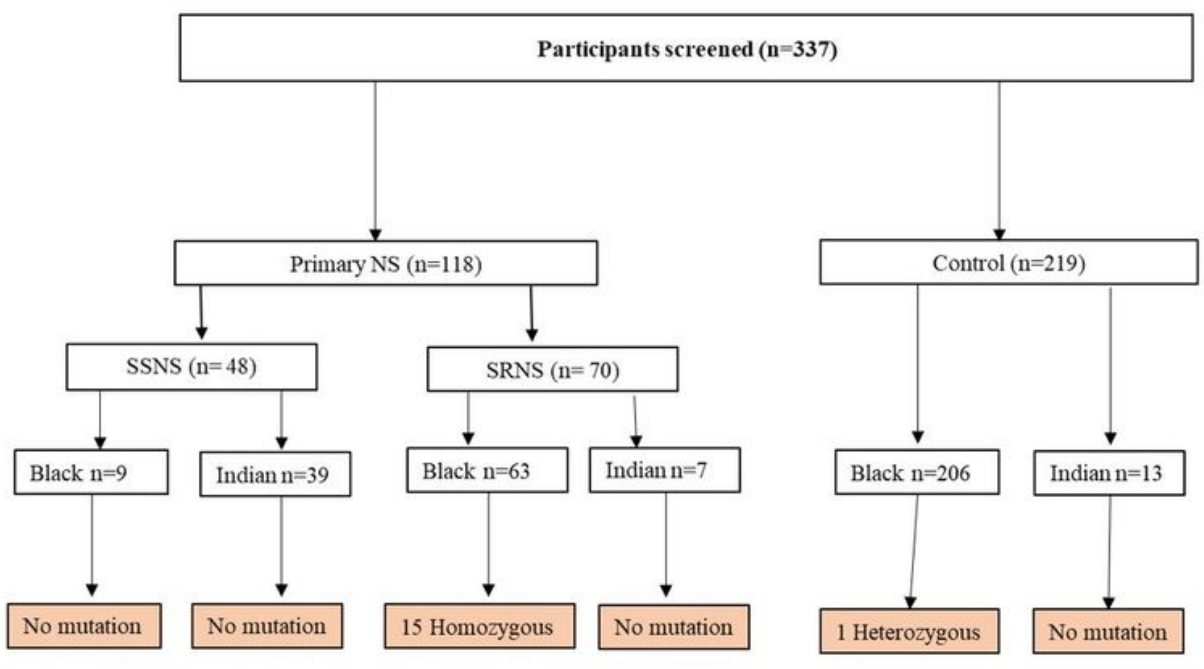

\begin{tabular}{|l|}
\hline Participants selected \\
for WES
\end{tabular}

Positive result of 10 genes filtered for causal variants

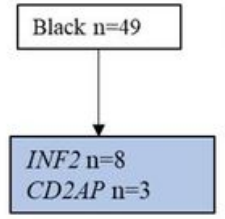

Indian $\mathrm{n}=7$

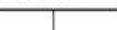

TRPC6 $\mathrm{n}=1$

\section{Figure 1}

Study population 


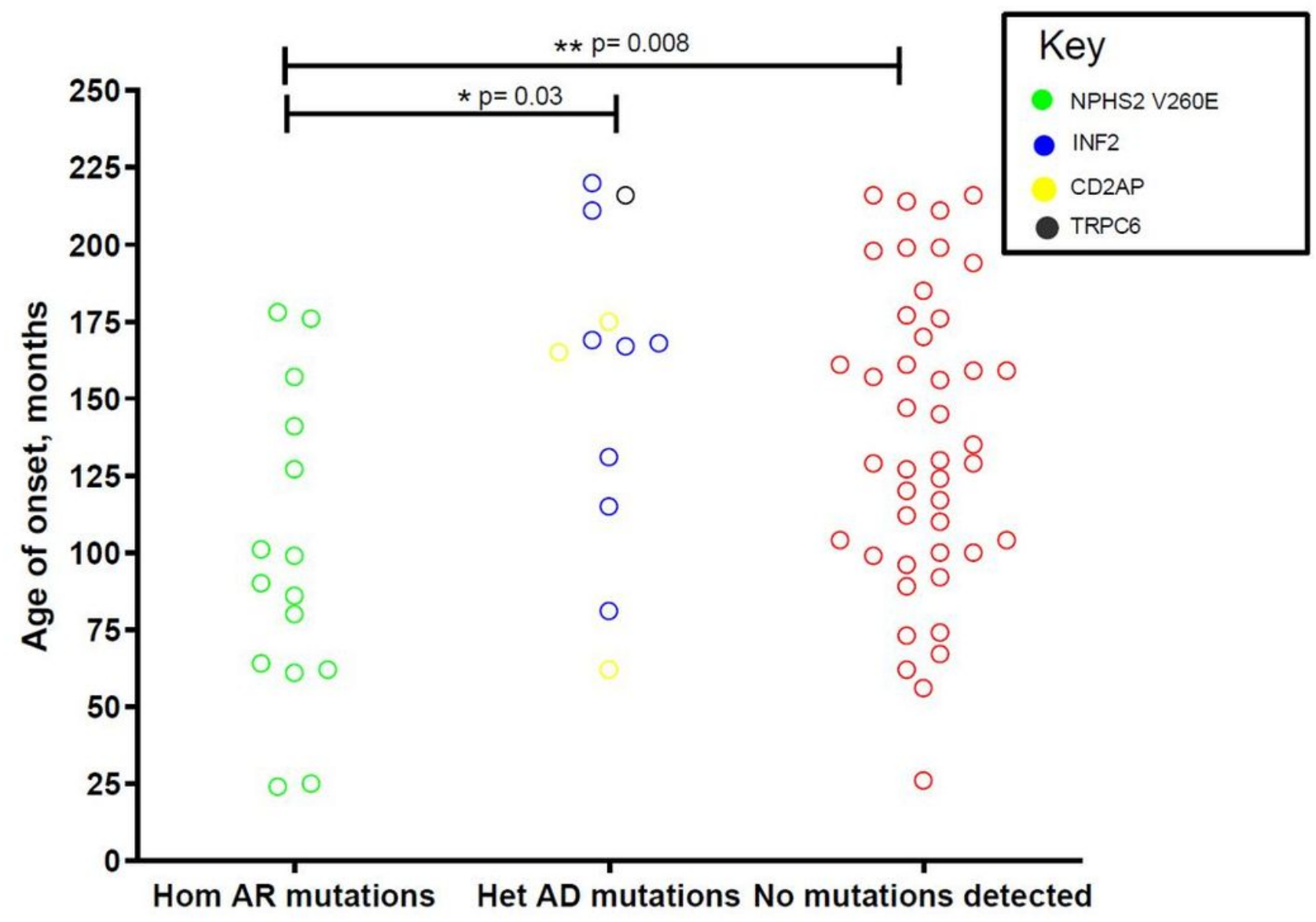

Figure 2

Comparison of distributions of ages of onset of steroid resistant nephrotic syndrome between carriers of the NPHS2 p.V260E, INF2 p.P516L and other (CD2AP p.K633R and TRPC6 p.G162V) variants. Distribution of age of onset was significant in NPHS2 p.V260E vs heterozygote autosomal dominant mutations ( $p=$ 0.03 ) and NPHS2 p.V260E vs no mutations detected ( $p=0.008)$. The $p$ value was calculated using one-way analysis of variance. 